\title{
VIAJES SOÑADOS A TRAVÉS DE LA HISTORIA. ¿DÓNDE HAS ESTADO, ROBERT? DE HANS MAGNUS ENZENSBERGER
}

\author{
Diana MUELA BERMEJO \\ Universidad de Zaragoza ${ }^{1}$ \\ dmuela@unizar.es
}

Resumen: La ficción onírica ha sido una de las temáticas constantes en la creación literaria infantil y juvenil. Asociada a las formas propias de la literatura adulta, el modelo de Carroll propuso maneras distintas de entender la lógica humana a través del sueño, y abrió todo un mundo de posibilidades narrativas que se alejaban del realismo moralista. En esta ficción se encuadra ¿Dónde has estado, Robert? novela de Hans Magnus Enzensberger que aúna, en un relato que contiene siete más, viajes soñados, saltos en el tiempo, enseñanza de la Historia y de las artes y buena parte de los componentes del bildungsroman. El objetivo de este artículo reside, precisamente, en delimitar las formas compositivas de la novela y tratar, así, de precisar la utilidad que tienen para el aprendizaje del lector joven y su posible inserción en los itinerarios lectores de los mayores de doce años.

Palabras clave: Viaje soñado, ficción onírica, novela histórica, viajes en el tiempo, literatura juvenil

1 Este estudio se encuadra dentro de las líneas de investigación del grupo ECOLIJ (DGA S45_17D), en el que me encuentro actualmente trabajando como investigadora. 


\section{VOYAGES RÊVÉS AU FIL DE L'HISTOIRE. LES SEPT VOYAGES DE PIERRE, DE HANS MAGNUS ENZENSBERGER}

Résumé: La fiction onirique a été l'un des thèmes constants de la création littéraire pour l'enfance et la jeunesse. Associé en principe aux genres de la littérature adulte, le modèle de Carroll a proposé des alternatives pour comprendre différemment la logique humaine à travers les rêves, et a ouvert un univers de possibilités narratives qui se démarquent du réalisme moraliste. C'est dans ce type de fiction qui serait classé le roman Wo warst du, Robert?, 1998 (fr. Les sept voyages de Pierre), de Hans Magnus Enzensberger qui combine, dans une histoire qui en contient sept autres, des voyages oniriques, des déplacements dans le temps, l'enseignement de l'Histoire et des Arts ainsi que de nombreux éléments du bildungsroman. Le but de cet article est précisément de délimiter les formes de composition de ce roman, pour essayer ensuite de préciser leur utilité pour l'apprentissage du lecteur jeune et son éventuelle introduction dans les itinéraires de lecture des enfants de plus de douze ans.

Mots-clés: Voyage de rêve, fiction onirique, roman historique, voyages dans le temps, littérature de jeunesse.

\section{ONIERIC TRAVELS THROUGH HISTORY. WHERE HAVE YOU BEEN, ROBERT? BY HANS MAGNUS ENZENSBERGER}

Summary: Oneiric fiction has been a recurrent topic in children's and young adult's literature. Carroll's model, which is associated to adult literature forms, offered alternative ways to understand human logic through dreams, and it opened up a new world of narrative possibilities, which broke away from moralist realism. Hans Magnus Enzensberger's novel Where have you been, Robert? can be classified in this tradition. This novel contains seven tales within a story, which includes dream travels, leaps in time, teachings of History and the Arts, and many other components of a bildungsroman. The goal of this paper is, precisely, to analyze the narrative structures of this novel and to pin down their 
usefulness for a young reader's learning process and its possible inclusion in the literary corpus for readers over 12.

Key words: Dream travel, oneiric fiction, historical novel, time travel, young adult fiction.

Desde que Lewis Carroll irrumpiera en el panorama de la literatura infantil consolidando el paradigma del viaje soñado a través de Alicia en el país de las maravillas, muchos han sido los escritores que se han atrevido a plantear ficciones oníricas que transportan a sus personajes geográfica o temporalmente. Clásico es ya, también, Donde viven los monstruos de Sendak, que abrió las puertas del libro álbum a un abanico amplísimo de posibilidades narrativas y compositivas, conduciendo a la revalorización del género que hoy experimenta en la literatura internacional.

Sin embargo, los viajes soñados están presentes en la literatura occidental desde sus orígenes conocidos, bajo distintas perspectivas y atendiendo a ideologías y temáticas diversas. Gómez Trueba (1999) analizó pormenorizadamente, y a partir de un corpus textual muy amplio, los detalles que componen el universo del viaje onírico, desde la Antigüedad clásica hasta las lecturas románticas. Esta obra determina, desde mi punto de vista, el análisis del discurso del género, que cabe ampliarse a la literatura infantil y juvenil, donde cobra especial relevancia.

No obstante, a pesar de la abundancia bibliográfica existente acerca del viaje soñado en la literatura destinada a un público adulto, todavía hoy se percibe una ausencia importante de estudios que analicen obras juveniles cuyos protagonistas experimentan viajes soñados. Parece contradictorio, dado el vasto conjunto de textos que rodean las obras de Carroll desde todas sus perspectivas, incluyendo, por supuesto, la de la ficción onírica (Montoya, 2005, entre otros).

A esto se añade, además, la relegación de la literatura juvenil a un claro segundo plano dentro de los estudios específicos sobre LIJ, dada la dificultad primera de delimitar el corpus y, en segundo lugar, debido al carácter variopinto de los textos que se incluyen bajo el marbete «juvenil»: «literatura juvenil, esa que en muchas ocasiones aparece como la hermana desfavorecida en ese binomio que en los medios especializados figura como indisoluble: la literatura infantil y juvenil» (López, 2013, p. 67). Dueñas reivindicó la heterogeneidad de algunas obras pertenecientes a la literatura juvenil -al margen de que buena parte de las obras presenten características similares-, en las que encontró un claro parentesco con la denominada «literatura popular» y propuso el criterio de Lluch como el más acertado 
Viajes soñados a través de la historia. ¿Dónde has estado, Robert? de Hans Magnus Enzensberger

para analizarlas atendiendo, no tanto a su calidad en términos categóricos, sino a su proximidad a la adscripción al canon o a la comercialización (Lluch, 1999, p. 57; apud Dueñas, 2008, p. 107).

Trato, pues, en este trabajo, de contribuir a llenar el vacío bibliográfico existente y a aportar más claves de selección para la caracterización y catalogación de la novela juvenil con el análisis de una de las obras que muestra de manera más paradigmática los términos en los que se expresa el relato de viaje onírico de finales del siglo XX: ¿Dónde has estado, Robert? de Hans Magnus Enzensberger.

\section{Perspectivas de análisis}

La novela de Enzensberger se sustenta sobre tres pilares teóricos: en primer lugar, y como punto de partida y marco compositivo general, el de los viajes oníricos, que preservan el paradigma tradicional de estructura sencilla y recurrente desde sus orígenes (Gómez Trueba, 1999). En segundo lugar, atendiendo al contenido que ofrece el texto, bajo la perspectiva de la novela histórica o de carácter historicista, entendiendo esta catalogación a través de la didáctica del género; es decir, de la novela como herramienta de enseñanza y aprendizaje para el lector joven. En tercer lugar, a partir de ciertos elementos del bildungsroman, que forman parte de la mayoría de novelas juveniles (Sáiz Ripoll, 2011 y López, 2013) y están presentes, más concretamente, en los relatos de viajes, tanto reales como soñados. Además de estos tres pilares, es necesario introducir después la perspectiva del análisis de la novela, en sí misma, como parte del proceso de formación del lector literario joven, ya no desde el contenido (historicista, ideológico, etc.) sino de la propia composición narrativa y del aprendizaje de los recursos que ofrece la literatura.

¿Dónde has estado, Robert? presenta a un joven de catorce años que había sido ya protagonista del gran éxito anterior de Enzensberger: El diablo de los números. La novela se publicó un año después, aprovechando el elevado número de ventas que había logrado con el acercamiento a algunos de los fundamentos de las matemáticas planteado en su best-seller anterior. Este dato me parece especialmente significativo, pues justifica la reducción de alguna de sus estrategias narrativas, cuya complejidad disminuye conforme avanzan las páginas del relato. El lector, familiarizado con la personalidad de Robert y deseoso de encontrarlo de nuevo en trepidantes aventuras, se desliza con él a través de un viaje onírico hacia el pasado, contemplando desde una perspectiva focalizada en el protagonista distintas etapas de la Historia: la Revolución Rusa, la Guerra de los Treinta Años, los inicios del nazismo, etc 
El viaje onírico que encuadra la acción narrativa se articula mediante la estructura clásica del género: exordio, sueño central/viaje y epílogo o despedida:

Generalmente el texto se abre con una introducción o pórtico, donde se explica y justifica la naturaleza onírica del relato que va a venir después. A continuación, tenemos el relato del sueño, que comienza con la descripción del escenario en el que va a transcurrir y sigue con la aparición de un personaje encargado de dirigir e instruir al soñador ante el desfile abigarrado de personajes y sucesos. Por lo general, el texto se cierra con un brevísimo epílogo donde se describe el despertar del sueño y en el que, sólo algunas veces, se expone una última conclusión final de todo cuanto ha sucedido. La simetría formal es evidente (Gómez Trueba, 1999, p. 168).

Además del mantenimiento de la tripartición general, el relato respeta la proporción que la tradición otorgaba a cada una de las partes, centrando la atención especialmente en el exordio y en el viaje y con un protagonismo menor del epílogo, pues las aventuras difuminan el esquema onírico externo:

La parte narrativa del sueño, aquella en la que se nos dice qué le ocurrió al protagonista en su sueño (a dónde viajó, con quién se encontró, etc.), normalmente va diluyéndose a medida que avanzamos en la lectura del texto, hasta llegar en algunas ocasiones a desaparecer por completo. En algunos casos extremos, una vez que nos adentramos en la obra, no hay descripción ni narración alguna, sólo discursos, interrumpidos a veces por alguna pregunta o algún otro discurso cuya función es reforzar lo que se ha dicho antes. El exordio viene a constituir así una especie de introducción al desfile casi siempre monótono que viene a continuación [...] No es extraño que el autor olvide hacer alusión al despertar [...] Lo más habitual, en cambio, es que súbita e inesperadamente el narrador despierte, el sueño se interrumpa y todo vuelva a su lugar (Gómez Trueba, 1999, pp. 207 y 250).

De esta manera, el viaje soñado de Robert puede incluirse dentro de las novelas de ficción onírica juveniles que siguen la estela de Carroll en la estructura externa, aunque ofrece al lector un contenido alejado de la fantasía lógica de Alicia (Montoya, 2005, pp. 1-4). En cualquier caso, la función del sueño en ¿Dónde has estado, Robert? continúa la filosofía romántica alemana, que encuentra en el sueño el único medio posible de acceder a la verdad y a la realidad, encubierta durante la vigilia:

según entendía la filosofía del romanticismo alemán, la unidad primigenia de la edad de oro, de aquel adánico paraíso primero en que habitó una vez el hombre, fue destruida por la razón; y a nosotros sólo nos cabe, para volver a ella, penetrar en el inconsciente, en lo irracional y, a través de los sueños, volver a reconstruirla (Comellas, 1999, p. 61).

El entendimiento irracional parte de los estadios intermedios de duermevela, y permite al escritor adentrarse en la complejidad interior del hombre, que los siglos XX y XXI explicarán en términos 
freudianos. En esta novela, Enzensberger plantea constantemente metarreflexiones oníricas y explicita las transiciones de la vela al sueño, y trata de desgranar la personalidad en formación de un adolescente de catorce años, en muchas ocasiones, a través del psicoanálisis. En este sentido, ¿Dónde has estado, Robert? no ofrece innovaciones con respecto a los textos clásicos de ficción onírica y mantiene, de manera paradigmática, las ideas sobre el subconsciente y la introspección del siglo XX, donde el sueño «igualmente, puede ser una salida a unas frustraciones demasiado marcadas» (Clancier, 1979, p. 69). Es interesante tener en cuenta la distinción entre procesos primarios y secundarios del aparato psíquico: en el primer caso, tiempo y espacio desaparecen, mientras que en el segundo la lógica ocupa un lugar principal (Clancier, 1979, p. 68). En los viajes oníricos de Robert, tiempo y espacio dejan de responder a las leyes de la lógica, pero no desaparecen por completo, puesto que intentan respetar la linealidad de sucesos narrados y las relaciones causa-consecuencia. Precisamente por ello, el sueño actúa sólo como marco, dejando paso a la novela histórica y al relato de aventuras en su estructura interna y alejándose, así, de la novela de Carroll (que ha sido analizada en términos de psicoanálisis; véase, por ejemplo, Skinner, 1973, pp. 314-347).

Por lo que respecta a la parte central de la novela, constituida por siete viajes soñados, puede ser también analizada bajo los presupuestos del relato de viajes, entre cuyas características la crítica incluye el viaje onírico -Cantizano, por ejemplo, los circunscribe en el ámbito del «viaje imaginario», a partir de Alicia y Los viajes de Gulliver como grandes clásicos del subgénero de viajes infantiles(Cantizano, 2005, pp. 14-15). Sin embargo, dentro del gran cajón que conforma la literatura de viajes, la ficción onírica engloba siete relatos que se insertan en la tradición de los viajes en el tiempo como subgénero de la ciencia-ficción. Así pues, ¿Dónde has estado, Robert? es una novela de viaje onírico en su marco compositivo general y, al mismo tiempo, como eje conductor de su estructura interna, un relato de viaje temporal hacia el pasado, con una marcada voluntad didáctica de enseñanza de la Historia.

Los viajes en el tiempo constituyen un asunto recurrente dentro de la literatura de ciencia ficción, bajo el padrinazgo de Julio Verne y de H. G. Wells. La crítica cita con frecuencia a Dickens en este ámbito, pero su Cuento de Navidad pertenece, a mi modo de ver, a otra tradición literaria, de carácter moralista y de estética realista, que se aleja de las recurrencias ficcionales y cientificistas de los viajes en el tiempo. La novela de Enzensberger cabe incluirse en la nómina de textos que, como decía, dominan 
Verne y Wells, y que Arranz enumeró en un estudio compilador de este tipo de obras (Arranz, 2014, pp. 76-79). La diferencia principal con el relato de Wells finisecular es, precisamente, la presencia de un objeto como generador del traslado temporal (Benchichà, 2015, p. 45) y, en este sentido, se inspira más en la introspección de Dickens, aunque con un tono notoriamente más distendido. Parece, pues, oportuno, incluirla bajo el marbete «ciencia-ficción soft», acuñado en los años 70 para describir a las novelas en las que el descubrimiento científico o el avance tecnológico que origina, por ejemplo, el viaje temporal es sólo utilizado para articular un relato «en el que predominaban las ciencias sociales» (Hesles, 2003, p. 93). Este término se opone al denominado «ciencia-ficción hard», a través del que en 1957 Peter Schuyler definió a la novela que atendía pormenorizadamente a los detalles técnicos y científicos (Hesles, 2003, p. 93). En ¿Dónde has estado, Robert? la presencia de un avance tecnológico como agente motor del viaje del tiempo es nula, si bien sí se describen dentro de los siete viajes soñados (vid. infra). Por otra parte, resulta especialmente importante la presencia de un elemento propio de las novelas de viajes en el tiempo que determina parte de la narración de Enzensberger: la de «evidenciar los riesgos que conllevaría para el futuro si se alterase el pasado» (Benchichà, 2015, p. 49). Robert, en la mayor parte de viajes, muestra elementos del futuro que rompen la linealidad temporal del pasado y la calma que esta produce en el resto de personajes, originando un avance súbito hacia el despertar o hacia el cambio de sueño (vid. infra).

Por lo que respecta al contenido de los siete viajes, ¿Dónde has estado, Robert? es un relato de aventuras de voluntad pedagógica y carácter historicista. En él domina el deseo de descubrir épocas pasadas y ambientes desconocidos, clave principal del éxito de este tipo de novelas desde los años 60 del siglo XIX (Letourneux, 2011, p. 53). El héroe, en este caso, es seducido por su propio inconsciente hacia aventuras oníricas regidas por los mismos principios que las aventuras reales dentro de la ficción, a saber: distanciamiento de la experiencia personal del lector con respecto a la de la ficción, deseo de explicar la realidad a partir de una lógica paralela motivada por el juego del relato, dotación de cualidades legendarias al héroe (nobleza, valentía, inteligencia, capacidad de amar, etc.) y transmisión ideológica de una serie de principios encarnados en personajes que adoptan una configuración maniquea (Letourneux, 2011, pp. 53-60).

Además, estas aventuras se desarrollan en un ambiente histórico que abarca una distancia temporal de cuatro siglos (XVII-XX) y que sirve a Enzensberger para mostrar al joven lector, desde su ideología, 
Viajes soñados a través de la historia. ¿Dónde has estado, Robert? de Hans Magnus Enzensberger

distintos momentos relevantes de la Historia contemporánea. En este sentido, ¿Dónde has estado, Robert? sigue la definición de novela histórica aportada por Fernández, que parte, a su vez, del consenso general de la crítica:

combinación de documentación histórica con personajes ficticios, y serán estos últimos los que nos introducen en determinado período histórico como a través de un túnel del tiempo y los que nos comunicarán el sentir de unas gentes que han formado parte de él pero permanecen en el más profundo de los anonimatos (Fernández, 2008, p. 103).

Dueñas insiste en la importancia de la hipertextualidad en la novela histórica juvenil, puesto que requiere «de complicidades intertextuales entre el autor y lector» (Dueñas, 2013, p. 2). Este aspecto es particularmente relevante en la novela de Enzensberger, pues el lector modelo al que se dirige parte, en el acto de lectura, o bien de las referencias intertextuales a las que remite cada uno de los viajes o bien a la necesidad de consulta de determinados hechos históricos, a través de pistas y del suspense como eje conductor del aprendizaje. Asimismo, el contenido y la composición formal del relato se enmarcan dentro de la caracterización de la novela histórica de los años 80-90, en la que la didáctica de la Historia constituía la razón principal de escritura, combinada después con ciertos elementos de la fantasía o el suspense (el autor describe esencialmente el caso español, pero parece una tendencia generalizada en la literatura juvenil europea):

\footnotetext{
De modo general, incidir en las enseñanzas del pasado parecía convertirse entonces en el resorte dominante de las narraciones históricas. Y, en este afán, no faltaron casos en que el didactismo se extremaba hasta convertir el relato en verdadera lección de historia [...] Más tarde, los autores tendieron a mezclar la dimensión histórica de los relatos con otros ingredientes como la fantasía o el suspense, prueba sin duda de que desconfiaban de la capacidad de atracción del pasado para el lector infantil y juvenil en los inicios de la era digital (Dueñas, 2013, p. 2).
}

Por otra parte, el aprendizaje de Robert a través de sus viajes oníricos constituye también un ejemplo de bildungsroman, hasta el punto de que se explicita el crecimiento interior del muchacho, con un juego entre el tiempo interno de los viajes y el tiempo externo de la ficción-marco. Sáiz Ripoll apuntaba que toda novela juvenil constituía una novela iniciática, puesto que las peripecias que experimentan los personajes construyen su identidad y su modo de comportarse en el mundo (Sáiz Ripoll, 2011, p. 7). Por viaje iniciático entiende «aquel que permite que quien lo realiza acabe siendo 
distinto y, a la vez, más rico y maduro. Es, por así decirlo, un doble viaje, hacia el exterior y hacia el interior» (Sáiz Ripoll, 2011, p. 8). Considera, además, los viajes oníricos como viajes iniciáticos mentales, puesto que contribuyen igualmente a consolidar la personalidad del sujeto y a hacerlo crecer interior y exteriormente (Sáiz Ripoll, 2011, p. 8). Las aventuras de Robert trascienden más allá del ámbito académico (es decir, del aprendizaje de la Historia) y se adentran en el terreno de las relaciones personales, tanto adultas como jóvenes, en las que se pondrá en juego no sólo su valor, sino también su honradez, tolerancia, amor y amistad. Por ello, se parte de una situación en conflicto con el medio en el que vive (familia y escuela), analizado en términos psicoanalíticos, que encuentran su cauce ideal en el sueño. Este punto de partida es característico de la novela de aprendizaje (López, 2013, p. 63) y se une al desenlace, en el que el héroe no sufre daños irreparables (López, 2013, p. 63).

Además, la personalidad de Robert encaja perfectamente con la caracterización de Lukács del protagonista del bildungsroman: solitario y «en una búsqueda constante de un sentido para la vida» (López, 2013, p. 64), que vive las aventuras de manera parcialmente pasiva «pues es objeto de una transformación no causada por él mismo, sino por las circunstancias en que vive» (López, 2013, p. 65). Este tipo de personaje tiene una función muy relevante en la literatura juvenil:

\footnotetext{
es un adolescente que se encuentra en una tesitura semejante, podríamos afirmar que no debe de existir un género literario en el que la simbiosis entre lector y personaje alcance unas cotas tan altas como en la novela de formación para un público joven [...] Es precisamente esa estructura formativa la que se ha convertido en uno de los más claros rasgos distintivos de la novela dirigida y leída por un público juvenil [...] Los procesos de maduración no tienen ya nada que ver con la supervivencia en un mundo hostil, sino más bien con la conquista de la autoestima en un mundo también hostil (López, 2013, p. 68).
}

Por lo tanto, el lector joven encontrará en ¿Dónde has estado, Robert? un referente de aprendizaje que aúna los recursos mnemotécnicos para el recuerdo de detalles históricos, una transmisión ideológica concreta y la posibilidad de empatizar emocionalmente con el protagonista en la búsqueda de su autoestima y crecimiento personales.

Finalmente, no debe desdeñarse el aprendizaje literario que ofrece la complejidad de las estrategias narrativas que, si bien son recurrentes en el marco general de la novela, contribuyen a que el lector profundice en su formación literaria y entre en contacto con fórmulas y recursos que aumentarán su grado de complejidad en futuras lecturas adultas. Así, la presencia de cajas chinas, analepsis, finales 
Viajes soñados a través de la historia. ¿Dónde has estado, Robert? de Hans Magnus Enzensberger

abiertos y elementos intertextuales cimientan un peldaño más de un itinerario lector que favorece otras experiencias lectoras, y aumentan el interés no sólo por el contenido de un relato sino por el placer estético de la lengua en la que está escrito y por la forma que lo compone.

\section{2. ¿Dónde has estado, Robert? como herramienta de aprendizaje}

El viaje soñado de Robert se articula mediante la siguiente estructura: prólogo (que corresponde exactamente con el exordio), núcleo de la narración (siete viajes soñados) y epílogo (despertar). El relato, pues, mantiene stricto sensu la estructura tradicional de la narración onírica, que conforma el marco general del subrelato -si se me permite el término-, en este caso, de aventuras a través del tiempo. Por lo tanto, la novela debe analizarse, como anunciaba al principio del trabajo, desde tres perspectivas: viaje onírico (marco de la narración y eje estructurador del discurso), novela histórica conformada a partir de viajes en el tiempo (caracterización de cada uno de los subrelatos que componen la novela) y bildungsroman construida mediante la concatenación de varias aventuras (relación entre los siete viajes y paralelismos narrativos de cada una de las historias). A través de estos tres pilares, Enzensberger aprovecha para servirse de la novela como herramienta de aprendizaje de la Historia, por un lado y de manera principal, y del arte, la ciencia y el costumbrismo de manera secundaria, pero determinantes para el desarrollo de la ficción. Por lo tanto, la novela conjuga perfectamente la máxima horaciana de prodesse et delectare aportando, simultáneamente, los elementos recurrentes que generan éxito entre los lectores jóvenes y una ambientación socio-histórica que avanza, de modo ligero, a través de todo el relato.

Por otra parte, la trayectoria literaria de Enzensberger define los objetivos de esta novela, que se publicó poco después de su best-seller El diario de los números. El autor, que cuestiona constantemente la sociedad capitalista, las miserias de la historia alemana y de la personalidad burguesa consumista (Jaeger y Torrent-Lenzen, 2002 y Dolle-Weinkauff, 2006) mantiene esta línea en ¿Dónde has estado, Robert?, en la que la enseñanza de la Historia se produce desde las críticas al capitalismo y a las veleidades del hombre, aunque, según apuntan Jaeger y Torrent-Lenzen, de manera más suave que en sus obras anteriores a los años 90: 
Aunque su obra poética refleje, como todos sus escritos, la evolución de la vida social y científica en Alemania, su poética no se deja reducir a una mera función reproductora de la realidad. Sobre todo a partir de los años 90, Enzensberger ha mostrado como poeta su vertiente más calmada, ofreciendo al público ingeniosas y profundas reflexiones sobre el yo, la sociedad y el individuo (Jaeger y Torrent-Lenzen, 2002, p. 21).

La idea principal que Enzensberger pretende transmitir en su novela aparece reflejada en un elemento paratextual: la cubierta, ilustrada con una fotografía de un ojo que, a su vez, remite en el recto que precede a la dedicatoria a un grabado de Jakob Böhme del siglo XVI, El Ojo que todo lo ve. En este caso, el ojo va enmarcado por una banda de Moebius que representa el Todo, el infinito, con la inscripción «Je länger, je lieber” ('Cuanto más tiempo, mejor’). Queda claro, pues, el sentido que Enzensberger atribuye a la novela: la contemplación de la historia, del tiempo y del pasado constituye el aprendizaje principal para el presente $y$, con ello, da el impulso necesario para que se desarrolle el bildungsroman y los viajes soñados que lo conforman.

El exordio, que corresponde con el Prólogo de la novela, se centra especialmente en presentar la personalidad de Robert y las condiciones sociales y familiares en las que se mueve. Esto resulta fundamental para la interpretación psicoanalítica de los sueños, en tanto que determina los comportamientos de otros personajes y su relación con el medio. Dos son las circunstancias que es necesario destacar: en primer lugar, su situación familiar, pues es un adolescente al que su madre y su padre (por separado) ignoran, y al que todos toman por extraño al mostrarse siempre soñador en el aula y en casa. En segundo lugar, manifiesta también cierto grado de cleptomanía, pues desea incontrolablemente quedarse con todo lo que está al alcance de su mano, hasta el punto de que su mejor amigo lo censura: «Ratibor, su amigo Ratibor, afirma incluso que Robert roba. Eso es un disparate, lo que ocurre es que Robert es distraído, echa el guante a todo lo que encuentra encima de la mesa y se lo guarda» (Enzensberger, 1999, p. 19). Este rasgo de su personalidad viene determinado por dos cuestiones, narrativa y descriptiva: sirve como justificación del carácter extraordinario del héroe y como desencadenante de varios finales de los viajes, pues Robert lleva consigo los objetos de su presente al pasado y la confusión que crea genera situaciones violentas que desembocan en la transición hacia otro espacio temporal.

Así, el joven protagonista de la novela es presentado, también, como un lector asiduo -«leía todo lo que caía delante de sus ojos» (Enzensberger, 1999, p. 18)- de memoria visual prodigiosa: 
Robert siempre lleva buenas notas a casa, pero en realidad es vago. Puede permitírselo, porque posee una memoria fantástica. No para lo que oye, ni para las palabras que tiene que empollar, sino para lo que ve. Le basta con mirar una vez la página del libro de francés, o las fórmulas en la pizarra... para almacenarlas, como si su mente fuera una película o un disquete (Enzensberger, 1999, p. 15).

El carácter excepcional del héroe es otra de las características habituales de la novela de aventuras:

Tout ce qui se produit dans l'œuvre sort de l'ordinaire, les personnages ne sont dotés, selon les mots de Robert Louis Stevenson, que d'un seul registre de qualités : le guerrier, le formidable [...] quant à l'univers mis en scène, il recherche toujours le dépaysement : spatial [...], temporel [...] il apparait comme l'espace dans lequel s'éprouve la valeur du héros et, dans la perspective de la littérature pour la jeunesse, l'espace initiatique conduisant à l'âge adulte (Letourneux, 2011, p. 53).

Efectivamente, el héroe de la novela de Enzensberger pone a prueba, a lo largo de su proceso de aprendizaje a través de la Historia, su valentía, su honradez, su empatía y su capacidad resolutiva. Sin embargo, la novela no termina de precisar cuál es el crecimiento emocional de Robert, ni en qué manera influyen sus experiencias personales para el comportamiento posterior en su medio social. Las peculiaridades de su caracterización como un adolescente extraordinario se quedan en el plano del exordio, sin ofrecer al lector una línea ascendente que culmine en el epílogo.

Por otra parte, la cleptomanía sirve, como decía, para situar el presente en el pasado, a partir de una selección arbitraria de objetos cuyo fin es maravillar con los avances científicos del futuro. Desde el punto de vista de la personalidad, este aspecto queda sin resolver, y aparece tan sólo con este fin utilitario: en el primer viaje soñado (a la URSS en 1956) Robert muestra un bolígrafo a la persona que lo protege y ella muestra su estupefacción hasta que, hacia el final del viaje, es interrogado por la KGB sobre esos objetos, que sospechan fruto del espionaje. El caso más extremo se plantea en el quinto viaje (a la Dinamarca del siglo XVIII) en el que un filósofo y científico enferma de gravedad al perder la razón por contemplar un objeto mucho más avanzado que el que él mismo había diseñado -una calculadora- con los medios de la época (Enzensberger, 1999, p. 188).

Además, los objetos sirven para conectar el presente y el pasado desde el punto de vista de la didáctica de la Historia, pues permiten cuestionar la presencia en el pasado de elementos y costumbres del presente, su utilidad y su valor en nuestra sociedad. Parten, parece claro, de la voluntad del autor de criticar el excesivo consumismo capitalista de finales del siglo XX pero, al mismo tiempo, pretenden 
suscitar en el joven lector un interés por el concepto de anacronismo y por el costumbrismo, este último analizado desde una perspectiva comparatista. Volviendo al ejemplo anterior del primer viaje, Robert se pregunta acerca de la existencia de los bolígrafos en 1956 (Enzensberger, 1999, p. 36), guiando así al lector hacia las preguntas que debe hacerse sobre las distintas épocas históricas más allá de la propia novela.

En general, la enseñanza de la historia sigue este carácter explícito y guiado que determina la presencia de objetos del futuro en el pasado. En cada uno de los viajes, Enzensberger sigue la misma línea pedagógica: intenta atrapar al lector partiendo del misterio (sin especificar dónde ni cuándo está Robert) para, paulatinamente, introducir varias pistas hasta determinar explícitamente la contextualización histórica. A partir de ahí se muestran, primero, las costumbres de las distintas épocas y, después, se desarrollan las aventuras. Sirva como ejemplo el viaje quinto, que mencionaba en las líneas anteriores, en el que el autor aprovecha al principio para mostrar, desde una perspectiva crítica y paródica, la vida caprichosa y banal de los personajes de la corte del siglo XVIII, los conocimientos científicos y artísticos y, después, la vida con un científico del momento. En el sexto viaje, a la Guerra de los Treinta años, se presentan las brutalidades de los enfrentamientos, los saqueos y los asaltos hasta desembocar en un barco, que da paso al viaje siguiente. Con independencia de si se trata de relatos de carácter más descriptivo o narrativo, estáticos o de ritmo vertiginoso, el objetivo principal radica siempre en la presentación de una sociedad que, a pesar del paso del tiempo, muestra los mismos vicios.

Las pistas, pues, poseen siempre carácter descriptivo, y corresponden con un paisaje, un objeto y, por supuesto, la vestimenta de los personajes que lo protagonizan. Véase, a este respecto, el viaje segundo como ejemplo (Enzensberger, 1999, pp. 60-62), en el que se define el paisaje australiano y el ambiente de los rodajes cinematográficos, que Robert al comienzo confunde con los Estados Unidos. El suspense queda siempre resuelto con la aparición de un cartel, periódico o elemento visual similar que explicita la fecha en la que se encuentra Robert, poco después del comienzo del viaje. Esta estructura viene determinada por las preferencias del lector implícito de la obra, que se decanta, en muchas ocasiones por la novela de enigma, el thriller, el terror y las aventuras (Muñoz y Hernández, 2011, 619-620 indican la preferencia femenina por este tipo de obras y la masculina por relatos de viajes y de ciencia ficción). Cualquier elemento de suspense aporta, para el lector joven modelo, un aliciente que 
propicia la continuación de la lectura de la novela, y el deseo de llegar a su conclusión. En este caso, el viaje onírico de Robert es, en sí mismo, misterioso, y a él se añade la indagación detectivesca del héroe para descubrir su ubicación, lo que confirman las palabras de Dueñas (2008, pp. 105 y 107) acerca de la repetición de esquemas y situaciones en la novela juvenil actual.

La enseñanza de la Historia se articula, pues, en función de los criterios y estructuras explicados en las líneas anteriores. Así, el lector se adentra en siete momentos distintos, siguiendo un orden cronológico decreciente: en primer lugar, la URSS de los años cincuenta; en segundo lugar, la sociedad australiana de mitad de los cuarenta; en tercer lugar, los inicios del nazismo en Alemania; en cuarto lugar, Noruega a mediados del siglo XIX; en quinto lugar, Dinamarca a principios del XVIII; en sexto lugar, la Guerra de los Treinta años y, por último, los Países Bajos en los inicios del XVII. En cada uno de ellos el objetivo didáctico es distinto, clasificándose, esencialmente, en tres grandes grupos: adoctrinamiento político (viajes primero y tercero), crítica costumbrista (viajes segundo y quinto) y acercamiento al arte pictórico (viajes cuarto y séptimo).

La descripción de las costumbres está presente en todos ellos, enfocada especialmente en el ámbito familiar a través de familias con problemas (en el segundo viaje, por ejemplo, se cuestiona el matrimonio y la figura paterna de los niños protagonistas; en el tercero, la violencia de un padre simpatizante con el nazismo; en el quinto, la relación lejana entre los miembros de la realeza y sus hijos, etc.). Todo ello pone de manifiesto, por un lado, la voluntad del autor de mostrar las consecuencias de las familias desestructuradas sobre los hijos y, por otro lado, de proyectar la visión que el propio Robert tiene de su familia, acercando el planteamiento de la novela al del sueño psicoanalítico.

Además, el arte tiene una presencia especial en esta novela, enfocado a través de personajes que explican las técnicas de las distintas épocas (como el pintor holandés protagonista del viaje séptimo, que enseñará a Robert en su taller y gracias al cual conseguirá volver a la realidad, o el pintor noruego del siglo XIX, que entabla amistad con el joven héroe); o bien de teóricos que muestran los movimientos más representativos de su momento (viaje quinto). En todos estos viajes (especialmente el quinto y el séptimo) Enzensberger detalla técnicas pictóricas que enseñan al lector nociones de arte alejadas de los planteamientos historicistas de, al menos, las escuelas españolas: 
El maestro se tomó una hora para enseñarle a triturar en el mortero los pequeños fragmentos cristalinos de mineral, y a molerlos después con agua pura y clara frotándolos durante horas con un mango que se adaptaba a la mano sobre la tabla pulida. Era una auténtica prueba de paciencia. En cuanto se secaba el polvo, había que volver a molerlo, esta vez con aceite o con una solución de cola. Cuando Robert hubo aprendido a tratar las tierras pardas y verdes, les tocó el turno a los pigmentos caros: carmín, azul de montaña y malaquita. Algunas substancias eran tan venenosas que el aprendiz tenía que vendarse la nariz y la boca para evitar respirar el color molido. El pigmento no podía machacarse ni muy grueso ni muy fino, para que los cristales conservasen su fuerza luminosa. El color terminado, que se preparaba todos los días, se guardaba en pequeños cuencos o conchas antes de que el maestro los aplicase sobre la paleta. También le enseñó a Robert un recipiente con un mineral transparente de color azul oscuro. Le dio a entender que era demasiado costoso para un aprendiz; ¡que no se le ocurriese ni rozar la botellita! El azul de ultramar de lapislázuli era el color más maravilloso de todos (Enzensberger, 1999, p. 230).

Esta voluntad de transponer al lector joven conocimientos que no se suelen enseñar en las aulas se relaciona también con las enseñanzas científicas de la obra (con un protagonismo menor que las artísticas) y que remiten, desde una perspectiva intertextual, a su obra anterior El diablo de los números. Centradas especialmente en el viaje quinto, Robert retoma su aprendizaje con el profesor Treibnitz (ficcionalización de Leibniz), en este caso, centrado en el sistema de numeración binario (Enzensberger, 1999, p. 185). La llamada al hipotexto es explícita: «Treibnitz lo miró de hito en hito, como si tuviera ante él a un diablo de los números» (Enzensberger, 1999, p. 185), pero el joven héroe no parece recordar su sueño anterior en este momento, lo que pone en duda la continuidad del personaje en esta novela con respecto a la anterior, pues, además, es narrada como si el protagonista fuera desconocido para el lector. En este pasaje, el objetivo de Enzensberger reside en que el lector joven averigüe el papel del científico y pensador alemán como autor de una de las primeras obras de cálculo infinitesimal: Nova Methodus pro Maximis et Minimis. Además, trata de suscitar interés por la biografía de Leibniz, perfilado en términos quijotescos como un científico que enloquece tras las horas en vela dedicado a las matemáticas. Enzensberger plasma, también, el alejamiento del científico de la corte real y la soledad de sus últimos años de vida, en este caso, insertando el anacronismo de la figura de Robert como justificación aparente a su alejamiento del mundo.

En general (y es el caso del viaje anterior), el tono de todos los relatos aporta a la historia un tinte dramático matizado siempre por la visión del propio Robert, consciente de la transitoriedad de su paso por la época en cuestión, lo que permite la aparición de la parodia en algunas ocasiones (como en el viaje quinto).

La educación en valores se desarrolla a partir del encuentro de Robert con una serie de personajes 
que muestran las consecuencias de la violencia (verbal, familiar, bélica) sobre la sociedad y el individuo (un bandido, un marido violento en la Alemania prenazi, etc.). Estos personajes son, en definitiva, proyecciones de la propia realidad de Robert (el bandido, por ejemplo, se asemeja sospechosamente a su amigo coetáneo Ratibor). De este modo, cada relato -focalizado en Robert- muestra dos personajes secundarios fundamentales: un enemigo que representa la violencia y la maldad, en términos paradigmáticos, y un amigo que le protegerá y que terminará perdiendo al finalizar el viaje. En este sentido, ninguno de los siete viajes plantea una estructura diferente, y todos ellos se encuadran nuevamente en los esquemas paradigmáticos del relato de aventuras juvenil. Mención especial merece el segundo viaje, en el que se inicia un misterio que queda sin resolver al final del cuento: la madre de la niña protagonista de la que se enamora Robert, aparece en el viaje siguiente (pocos años antes), por lo que el lector espera que se explique su historia (qué le ha llevado al fracaso de su matrimonio). Sin embargo, esta historia queda en el aire, dando paso a otros marcos temporales que nada tendrán que ver con estos últimos.

Por lo tanto, y en términos generales, la educación en valores que transmite ¿Dónde has estado, Robert? no ofrece al lector adoctrinamientos morales que no haya podido encontrar previamente en otros textos similares o que difieran de la tónica habitual de la literatura infantil, sino que responde a planteamientos maniqueos representados por personajes que encarnan, de un modo arquetípico, las figuras del bien y del mal. Mayor complejidad plantea, sin duda, la construcción narrativa, donde el lector modelo sí podrá poner en marcha una lectura formativa que le abra las puertas hacia otras novelas formalmente más ricas.

\section{La construcción narrativa y la formación del lector literario juvenil}

Especialmente interesante resulta, en ¿Dónde has estado, Robert?, la inmersión del relato marco en el espacio onírico y las técnicas narrativas que surgen de su desarrollo. La novela comienza in medias res, anunciando el alejamiento del protagonista de su realidad hacia un misterio todavía insondable: «El día en que Robert desapareció era un día normal y corriente, y lo más asombroso de su desaparición es que nadie la notó, ni siquiera su madre» (Enzensberger, 1999, p. 13). La novela une principio y final en una estructura circular en la que los viajes oníricos de Robert sólo son conocidos por él mismo, sin que trasciendan a su entorno. Sin embargo, la naturaleza onírica del viaje llega a ser 


\section{Diana MUELA BERMEJO}

cuestionada en el epílogo:

Cabía pensar que todo ha sido un sueño. A Robert, sin embargo, una idea tan absurda le provoca risa. Él lo sabe mejor que nadie. Sabe perfectamente que hace apenas un instante, es decir, hace cerca de cuatrocientos años, se encontraba en un lugar completamente diferente. Lo que sostiene en la mano no es un bocadillo de jamón, sino un pincel, y la substancia que gotea sobre el suelo de la cocina y que parece sangre es barniz de granza del platillo de su maestro David, que ya llevará muerto mucho tiempo (Enzensberger, 1999, p. 248).

La presencia del objeto prueba la veracidad de los viajes temporales dentro de la ficción. No obstante, todo el relato, incluido el despertar, se articula como un viaje onírico, que sólo se cuestiona en los últimos párrafos. La idea es, en última instancia, sembrar en el lector la duda acerca de la verdadera naturaleza de las experiencias de Robert, y alejarlas en gran medida de la explicación novelesca tradicional del sueño. No me parece apropiado, sin embargo, analizarlo únicamente como un viaje en el tiempo, pues, en general, no cumple con los elementos principales de este tipo de obras de cienciaficción (presencia de una máquina del tiempo, explicación científica de la posibilidad de saltar al pasado o al futuro, personajes que deseen voluntariamente transgredir la linealidad de la percepción humana de la realidad, etc.). Robert viaja al pasado involuntariamente, y lo hace siempre a través de recuerdos e imágenes que ha visto o vivido en el presente y que almacena en su excepcional memoria. Por otra parte, el sentido de la vista juega un papel crucial, puesto que de él depende la transición entre los viajes y la inmersión en el mundo onírico. En mi opinión, pues, la novela debe ser analizada en términos oníricos, puesto que los viajes en el tiempo como avance científico constituyen únicamente una posibilidad que se abre al final del texto.

Así, el grabado de Böhme apunta también el hilo conductor de la narración, no sólo simbolizando cómo debe ser entendida la Historia, sino abriendo también las puertas al marco narrativo del sueño. De este modo, el propio Robert describe con gran precisión cómo se desarrollan estos viajes, y explicita su condición onírica:

Le basta con cerrar los ojos, por ejemplo, antes de quedarse dormido, para que comience. Primero aparecen unas manchas claras y oscuras que se mueven de arriba abajo, como en una pantalla. ¡Aburrido! Luego vienen las bandas violetas y verdes, un tanto temblorosas, a veces gruesas, otras más finas, y al poco tiempo aparecen serpientes de colores, cada vez más serpientes, un carnaval de fuego centelleante. Entonces sólo tiene que frotarse muy suavemente con los nudillos los párpados cerrados. Del abigarrado dibujo emergen ya las primeras imágenes: un mar de color naranja, con olas blancas, bandadas y bandadas de pájaros que cruzan azules un cielo de color gris lila, grandes helechos, barcos pequeños pero veloces con velas crepitantes. Por último las figuras: bailarines vagos como sombras en un sótano o luchadores que ruedan por la hierba. En algún momento aparece siempre su enemigo, el cocinero gigantesco de gorro blanco; pronto empezará a 
gritarle a Robert, pero sus fauces muy abiertas no emiten el menor sonido... Como es natural, nadie sabe lo que ve Robert antes de quedarse dormido (Enzensberger, 1999, pp. 14-15).

El espacio onírico detallado en términos sensoriales y sinestésicos conecta, también, con el hipertexto de la obra de Enzensberger, puesto que la descripción de los sueños es especialmente relevante en El diablo de los números, en la que Robert aprende matemáticas justamente mientras sueña-véase, por ejemplo, la descripción recurrente del tobogán interminable como la mayor pesadilla del muchacho (Enzensberger, 2017, p. 11)-.

La causa física de este prodigio parece radicar en la vista del chico, puesto que le sucede siempre que se frota los ojos mientras ve una imagen. Esto resulta especialmente importante por dos razones: en primer lugar, porque él es consciente de su propio estado, lo que desemboca en fragmentos de metaanálisis del sueño donde no sólo razona sobre el proceso, sino también sobre su temporalidad; $\mathrm{y}$, en segundo lugar, porque a lo largo de toda la novela surgen referentes reales para los sueños de Robert, tales como películas, cuadros o álbumes de fotos. La primera inmersión al mundo soñado se produce, por ejemplo, mientras Robert ve un documental o película sobre la Rusia de los años cincuenta; la segunda mientras ve en el cine una película de aventuras. Paulatinamente, la pintura va adquiriendo una importancia mayor, pues un buen número de los viajes se producen al introducirse Robert en la imagen pictórica que contempla, hasta el punto de tener que recrear su propia realidad en un cuadro para que se produzca el despertar. Es muy frecuente en la novela la explicación precisa del origen del sueño, a partir de referentes reales:

\footnotetext{
La escena le recordó a Robert una obra de teatro que había visto en cierta ocasión | Conocía estas escenas por las innumerables películas de espías que había visto | Conocía el nombre de la ciudad por el atlas escolar | Robert lo sabía porque había visto por lo menos doscientas películas policíacas en la sesión de noche cuando su madre salía de casa | Era uno de esos modelos americanos que Robert sólo conocía por películas antiguas, un viejo Buick [etc.] (Enzensberger, 1999, pp. 32, 39, 43, 48, y 62).
}

Además, esta recurrencia a referentes reales permite también la inserción de la estructura de cajas chinas en la novela, enriqueciendo su composición narrativa. El viaje segundo se inicia tras el visionado de Robert de una película, estando todavía sumergido en el primer sueño ruso. El tercero, a su vez, surge a partir de un álbum de fotos antiguas que Robert sostiene entre sus manos, que le 
conduce a la realidad de una de las fotos. En el cuarto, un libro de estampas situado en la librería en la que se esconde tras huir de los nazis le conduce a Noruega en el siglo XIX, y así sucesivamente. A esta estructura de sueño dentro del sueño se añade un caso de analepsis, dentro del exordio: la narración sitúa a Robert en su casa, por la noche, mientras su madre se prepara para acudir a una cena de gala. En ese momento, ella le prohíbe frotarse los ojos, pues atribuye al gesto la causa por la que su hijo se muestra alejado del mundo y sumergido en su pensamiento en no pocas ocasiones. Robert recuerda la vez que tuvo que acudir al oculista, instado por su madre, para revisarse la vista, y ese relato médico configura una analepsis que se encuadra bajo la oración «Todo normal» (Enzensberger, 1999, pp. 1418), enunciada por el oftalmólogo. Sin embargo, éste es el único caso de analepsis en la novela, más allá de algún recuerdo puntual (que no constituye un relato extenso del pasado) al que le conduce su pensamiento dentro de cada viaje soñado. Interesante es, también, un caso de sueño dentro del sueño, en la línea de esta estructura de caja china, producido en el primer viaje. No obstante, no se detalla el contenido de ese sueño, sino simplemente su origen (Enzensberger, 1999, p. 30).

Por otra parte, Robert analiza en varias ocasiones la irrealidad de sus viajes, tratando de dotarlos de una apariencia temporal mensurable, que avanza progresivamente hasta el despertar, en el que se concluye el lapso temporal transcurrido entre el exordio y el epílogo. Ejemplo de ello es, nuevamente, el primer espacio soñado, en el que Robert es encarcelado por sospecha de espionaje y se explicita la duración de su encarcelamiento; o, poco después, cuando es trasladado en tren hacia los dirigentes superiores de la KGB:

La situación permaneció invariable durante días [...] Cualquiera hubiera podido pensar que el tren viajaba en círculo. Después de varios días, cuando uno de los soldados de guardia levantó al amanecer la persiana enrollable de la ventana, Robert divisó a lo lejos una cadena montañosa de una blancura deslumbrante (Enzensberger, 1999, p. 45).

Este metaanálisis del sueño culmina en el segundo viaje, en el que Robert trata de describir los sentimientos que le producen los saltos temporales:

Robert se sentía como un sonámbulo en pleno día. Era una sensación extraña la de vivir la escena por segunda vez, sólo que en esta ocasión no la veía desde fuera, acosado por el miedo, en la oscura sala de un cine de Moscú, sino desde dentro, en una película que se estaba rodando Dios sabe dónde, en un paisaje de cuento junto al mar... [...] Nunca había llegado alguien más deprisa que él a Australia desde Moscú... Más 
deprisa que con el avión a reacción más rápido. Y sin billete, ni dinero, ni cinturón de seguridad. En realidad, una forma ideal de viajar [...] ¿Habría ido a parar a la escena final? ¿Sería él, Robert, uno de los actores? Pero el cine de Moscú proyectaba una película rodada hacía mucho tiempo, antes de que él llegase a Australia. ¿O quizá sucedió después? Si seguía reflexionando más tiempo sobre el asunto, acabaría volviéndose loco, seguro (Enzensberger, 1999, pp. 60, 63 y 67).

Y, por último, reflexiona sobre la relatividad temporal:

\begin{abstract}
Al menos ahora ya no sólo sabía dónde estaba, sino también cuándo. Además de los lugares, también se habían confundido las épocas. En cierto sentido, Robert parecía moverse continuamente hacia atrás o, mejor dicho, hacia atrás y hacia delante al mismo tiempo. Tenía que reflexionar a toda costa sobre ello (Enzensberger, 1999, p. 68).
\end{abstract}

La focalización del relato es, por lo tanto, interna y fija en el personaje de Robert. Evidentemente, la condición onírica de la narración exige una focalización en quien la experimenta, aunque esto no siempre se cumpla en términos narratológicos. Robert es quien vive el cuento, quien reflexiona sobre él y a través de quien el lector conoce la historia y a los demás personajes. Tanto es así, que sabemos de ellos tan sólo lo que Robert conoce, y pierden su identidad mientras el protagonista no se haya adentrado en ella: «Paciencia -dijo el profesor. Como no se había presentado, Robert siguió llamándolo as'”" (Enzensberger, 1999, p. 48). Los ejemplos de la focalización son muy numerosos, basta con uno paradigmático para mostrar el tipo de narrador de la novela: «Fue entonces cuando debió de pillar ese sello. Sí, la señora Korn tenía razón. A veces estaba ido de verdad... ¡Qué costumbre más idiota! Si le encontrasen ese chisme encima sí que sospecharía en serio de él y con toda la razón del mundo» (Enzensberger, 1999, p. 48).

Como en este caso, la focalización interna termina desembocando en un monólogo interior cuando se plasma el pensamiento lógico de Robert, lo que sucede de manera continuada. Además, resulta fundamental si se tiene en cuenta el lector modelo, pues la empatía que busca lograr el autor con la visión del mundo de un joven de catorce años sería más difícil si la narración focalizase en un personaje adulto, fuera interna variable o, simplemente, externa. La mayoría de los protagonistas de novelas juveniles son personajes jóvenes, en aras de que el público se identifique con el personaje como sucede con otras corrientes literarias adultas (véase, por ejemplo, el teatro burgués del siglo XIX como paradigma de esta tendencia).

Por otro lado, la focalización interna permite al autor adentrarse con mayor profundidad en la 
descripción de los sentimientos amorosos de Robert, que experimenta en dos de los viajes (segundo y quinto). En el segundo, su amistad con Caroline desencadena unos sentimientos más profundos de los que experimenta en el relato danés, en el que se encapricha de la joven princesa de la corte: «Él la estrechó entre sus brazos, y la mantuvo abrazada hasta que se disipó su furia» (Enzensberger, 1999, p. 77). En este momento sufre su primer desengaño, lo que contribuye a su transición a la vida adulta y a conformar el bildungsroman que es, en definitiva, ¿Dónde has estado, Robert?:

- Hubierais debido ver la mirada de perro con la que me pidió que os presentara sus insulsos respetos [...].

- ¡Que se figure lo que quiera! - exclamó la princesa [...]

Se juró no volver a caer en las miradas de reojo de una cabra mimada y antojadiza. Sí, cabra la llamó preso de la ira, y sólo el danés que roncaba a su lado le impidió dar rienda suelta a su decepción (Enzensberger, 1999, pp. 176-177).

Este crecimiento personal viene determinado por cada una de sus experiencias a través de la Historia, algunas de ellas de especial crudeza (como el ajusticiamiento de su amigo Radomir, ficcionalización de Ratibor) o el maltrato a su abuela y a su bisabuela por parte de su bisabuelo, en plena Alemania nazi. La enseñanza se centra, así, en las terribles consecuencias físicas y psicológicas de la violencia, y en la necesidad de apreciar el cariño humano cuando es gratuito. Tanto es así, que el crecimiento emocional se mide en los años transcurridos, como si fuera asociado a un crecimiento físico que no será perceptible en la realidad coetánea: «Desde ahora Robert es dos años mayor que todos los demás de la clase. No se le nota porque se pintó dos años más joven. Pero, si sale a relucir, se armará una de mil demonios. Y es que sabe demasiado» (Enzensberger, 1999, p. 148).

El final queda cerrado con el retorno de su madre al hogar, arrepentida y deseosa de recuperar la relación con su hijo, y con la recopilación explícita de la idea principal de cada viaje (Enzensberger, 1999, pp. 250-251); sin embargo, varias de las incógnitas abiertas durante los viajes soñados quedan abiertas, permitiendo una continuación de la novela que, hasta el momento, no ha visto la luz.

\section{Conclusiones}

¿Dónde has estado, Robert? es, pues, una novela configurada a partir del paradigma clásico de relato soñado y del viaje temporal que ofrece al lector joven ciertas particularidades narrativas que pueden enriquecer su formación literaria.

En primer lugar, la enseñanza de la Historia se erige como función principal de la narración, 
enfocada siempre desde una ideología anticapitalista y pacifista que se aleja voluntariamente de la violencia bárbara de determinados momentos históricos. En este sentido, Robert crecerá como adolescente al contemplar las consecuencias de la violencia y, al mismo tiempo, conocerá algunos detalles de las costumbres de otros siglos, y sus paralelismos con la época presente. Así, el grabado de Böhme resume la idea de contemplar todo el pasado para comprender bien el presente, que articula el texto centrado especialmente en las épocas moderna y contemporánea. Por otro lado, ocupan un lugar especial las ciencias y las artes como parte del conocimiento necesario para la formación del individuo, desde planteamientos poco habituales en las aulas.

En segundo lugar, la novela transmite, a través del comportamiento del héroe y de la relación con otros individuos del medio histórico en que se mueve, ciertos valores ligados a la novela de aventuras (valentía, honestidad, amor, lealtad) que resultan frecuentes en las obras juveniles también y que forman parte del proceso de aprendizaje de Robert configurando, así, un bildungsroman más dentro del corpus infanto-juvenil. No debe desdeñarse, pues, la importancia del error y de la confusión dentro de la novela, lo que resultaría enormemente interesante para ser analizado en términos de comportamiento emocional adolescente.

En tercer lugar, las técnicas narrativas que configuran el texto plantean una complejidad mayor a la de otros relatos, y permiten al lector joven aprender y desarrollar su competencia literaria más allá del contenido argumental, dando cabida a recursos formales que encontrarán en lecturas adultas de manera mucho más compleja. Cajas chinas, analepsis, metarreflexión acerca del propio relato y estructura aparentemente circular son algunos de los elementos que el lector joven descubrirá conforme avance entre sus páginas, alejándose de la linealidad de la ficción narrativa que predomina en muchos de los textos que, posiblemente, formarán parte de su itinerario lector.

Resta, ahora, analizar en profundidad el tratamiento de la Historia desde una perspectiva especializada, con el fin de discernir entre la ideología encubierta que se esconde bajo cada uno de los viajes y la enseñanza canónica, y de situarla en la didáctica de la Historia planteada, de acuerdo con la tradición, en términos de ficción.

\section{Referencias bibliográficas}

Arranz, D. F. (2014). La literatura de viajes en el tiempo: orígenes e hitos. Crítica, 990, 76-79.

Benchichà López, N. Y. (2015). Un recorrido por los viajes en el tiempo en la ficción internacional, en 
C. Cascajosa y J. Olivares (eds). Dentro de El Ministerio del Tiempo: el libro sobre la serie que ha revolucionado la Televisión en España (pp. 45-54). Madrid: Léeme.

Cantizano Márquez, B. (2005). Tipología del viaje literario. Primeras Noticias. Revista de Literatura, 212, 7-16.

Clancier, A. (1979). Psicoanálisis. Literatura. Crítica. Madrid: Cátedra.

Comellas Aguirrezábal, M. (1999). El viaje onírico de la poesía romántica. Algunos ejemplos españoles, en M. Maldonado y E. Parra-Membrives (Eds.), Lo irracional en la literatura (pp. 61-98). Berna: Peter Lang.

Dolle-Weinkauff, B. (2006). Postmodernism in contemporary German picture books. An outline of the books by Hans Magnus Enzensberger. Anuario de Investigación en Literatura Infantil y Juvenil, 4, 3-19.

Dueñas, J. D. (2008). Literatura juvenil actual: receptor modelo, literatura popular y canon estético. Lenguaje y Textos, 27, 105-117.

Dueñas, J. D. (2013). Hipertextualidad y formación cívica en la novela histórica infantil y juvenil, en L. P. Cancelas, R. Jiménez, M. F. Romero y S. Sánchez (Eds.), Aportaciones para una educación lingüistica y literaria en el siglo XXI (pp. 1-9). Granada: GEU Editorial.

Fernández-Tresguerres Velasco, M. L. (2008). La novela histórica juvenil, en S. Montemayor (Coord.), La novela histórica como recurso didáctico para las ciencias sociales (pp. 95-146). Madrid: Ministerio de Educación, Cultura y Deporte. Subdirección General de Información y Publicaciones.

Genette, G. (1989). Figures III. Barcelona: Lumen.

Gómez Trueba, T. (1999). El sueño literario en España. Consolidación y desarrollo del género. Madrid: Cátedra.

Enzensberger, H. M. (1999, $1^{\text {a }}$ ed. alemana 1997). ¿Dónde has estado, Robert? Madrid: Siruela.

Enzensberger, H. M. (2013, $1^{\text {a }}$ ed. alemana 1998). El diablo de los números. Madrid: Siruela.

Hesles Sánchez, G. J. (2003). El viaje en el tiempo en la literatura de ciencia ficción española. Tesis Doctoral. Universidad Complutense de Madrid. Accesible en línea: http://eprints.ucm. es/21401/1/T34464.pdf [Última consulta: 4/9/2018]

Jaeger, A.; Torrent-Lenzen, A. (2002). Erudición y poética en la obra de Hans Magnus Enzensberger. 
Cuadernos del Ateneo, 13, 18-26.

Letourneux, M. (2011). La mauvaise foi du roman d'aventures. Les Cahiers du CRIL. Littérature du grand large: aventures et voyages, 3, 53-60.

López Gallego, M. (2013). Bildungsroman. Historias para crecer. Tejuelo: Didáctica de la Lengua y la Literatura. Educación, 18, 62-75.

Lluch, G. (1999). Los noventa: ¿nuevos discursos narrativos?. En VVAA, VII Jornadas de Bibliotecas Infantiles y Escolares. Literatura para cambiar un siglo (pp. 47-71). Salamanca: Fundación Germán Sánchez Ruipérez.

Montoya, V. (2005). La realidad onírica de Lewis Carroll. Primeras Noticias. Revista de Literatura, $212,43-46$.

Muñoz Rodríguez, J. M.; Hernández Martín, A. (2011). ¿Hábitos lectores de los alumnos de la ESO en la provincia de Salamanca? ¿Son el género y el entorno factores diferenciales?. Revista de Educación, 354, 605-628.

Sáiz Ripoll, A. (2011). Tiempo de iniciación. El viaje iniciático en la literatura infantil y juvenil actual. CLIJ: Cuadernos de Literatura Infantil y Juvenil, 244, 7-18.

Skinner, J. (1973). Lewis Carroll en el país de las maravillas. En H. M. Ruitenbeek (Ed.), Psicoanálisis y literatura. Méjico: Fondo de Cultura Económica. 